\title{
Innovations and Practices that Influence Patient-Centered Health Care Delivery Special Series
}

The publication of this special series on Innovations and Practices that Influence Patient-Centered Health Care Delivery was intended to report on research that focused on innovative practices and interventions that influence what matters most in health care: the patient. It was proposed to the Editor in March 2020, only a few weeks before many jurisdictions in the U.S. went under pandemic control measures in response to the emergence of the novel coronavirus 2019 (COVID-19) including curfews, stay-at-home orders, and other widespread restrictions.

For most, the pandemic has been extremely difficult with isolation and loss impacting individuals and groups across communities and countries. Amidst this chaos, grave racial and social injustices surfaced and served to heighten awareness about inequities that permeate health care systems and delivery. The 15 papers in this special series all focus on practices in patient-centered care, with some directly addressing issues related to the pandemic and racial and social inequities. In this editorial, we highlight four papers that reflect the breadth of practices that influence patient-centered health care delivery, and also focus on the important issues of responses to the pandemic and health equity considerations.

Lai and colleagues highlight the challenges associated with the deployment of primary care physicians (PCPs) to inpatient settings during the pandemic. They provide recommendations for developing a clinician-friendly and sustainable transitional workflow to overcome existing problems such as PCPs lack of up-to-date training to deliver inpatient care, workflow and technology challenges, and fatigue due to the need to work extended hours. Reportedly, nearly $31 \%$ of PCPs noted experiencing burnout, and those serving in organizations that provide pandemic-related care had a higher risk of burnout. The authors propose three practices to address these problems. First, hospitals should have a transition plan in place for PCPs to adopt new practices (e.g., functioning in a team) to effectively deliver care in a dynamically changing environment. Second, a comprehensive orientation plan should be implemented for PCPs that includes orientation to policies and team member responsibilities. Third, they propose matching inpatient providers such as hospitalists or residents with PCPs with this matching process designed to promote learning, prevent burnout, provide opportunities to shadow inpatient providers, and develop social support. The authors suggest these important practices can be applied to promote successful collaboration as PCPs are introduced to inpatient settings to extend the capacity of hospitals to deliver necessary care in response to an emergency such as the COVID-19 pandemic.

Olayiwola and colleague present a call to action, making the case that health equity should be the moral imperative around which the Quadruple Aim of health care delivery should realign. They argue that addressing health care quality alone does not necessarily lead to an elimination of inequities and disparities in health care. Reflecting upon recent issues in the U.S., they describe how Black communities face oppressive social injustice and systemic racism, making them disproportionately vulnerable to the pandemic and health disparities. They then propose four actions to consider for a successful shift from the current paradigm to one that is centered around health equity: confronting a painful truth, shifting focus to accuracy and precision, applying a health equity lens, and aligning incentives. In their discussion about the third action, as an example, the authors describe a prototypical practice led by Multnomah County, Oregon, where practitioners created a Health Equity and Empowerment Lens worksheet and framework that probes existing practices "required to uproot inequities upstream, midstream and downstream (page 4)." The Quadruple Aim, the authors argue, can only be achieved with a high level of precision if there is an honest focus on the implications of health care practices on the most vulnerable people in our society.

Jonnalagadda and colleagues provide an overview of patient-centered practices in the domain of social determinants of health (SDoH) that dovetails with Olayiwola and colleagues' proposed paradigm shift. The authors of this paper argue that practices that involve increasing awareness of and addressing SDoH are important precursor actions to reducing disparities and achieving health equity. Despite this recognition, they note that health systems generally lack the ability to effectively capture and utilize information about patients' SDoH. One cost-effective approach to capturing this information they present is the use of area-level SDoH measures, which reflect aggregate measures of SDoH at the neighborhood level. Examples of countries such as New Zealand and the U.K. are presented to illustrate how the incorporation of area-level SDoH measures can be successfully achieved and what benefits may be realized. For example, the New Zealand Index of Deprivation, in its 
fifth iteration, is used for practices that include guiding resource allocation, community advocacy, and research. Recently, a similar trend was adopted in the U.S., wherein community vital signs were incorporated into an electronic health record system to enable identification of geographic variability in outcomes. Targeting resources based on geographical disparities as indicated by $\mathrm{SDoH}$ indices can help to bridge the health inequity gap and contribute to efforts to manage scarce resources. The authors conclude their discussion by presenting sobering evidence that even with SDoH data, gaps remain in the ability of individuals to obtain assistance based on findings from SDoH screening. They describe critical barriers that may contribute to this problem and call for additional studies that extensively document approaches that can reduce barriers to integrating and using SDoH information.

Anderson and colleagues, in their study of the facilitators and barriers to adherence with adjuvant endocrine therapy (AET) among breast cancer survivors, highlight just how complicated it can be to develop and successfully implement a patientcentered intervention. Their innovative mHealth application supports both symptom management and medication adherence and considers three dimensions: symptom experience, management strategies, and health outcomes. As part of their study's Participatory Action Research design, the study team conducted post-RCT focus groups to obtain perspectives about the effectiveness of the application and its sustainability over time from study participants. Data from these focus groups indicated a need to tailor the intervention for different racial groups. For instance, the opportunity to present racially and culturally concordant content on the application was noted as important as this could improve patient-provider communication, a critical issue among Black women who have experienced high disparities in breast cancer outcomes.

The articles we have highlighted in this editorial reflect a meaningful breadth of innovations and practices in patientcentered care that have been studied during a time that was unprecedented and hopefully never repeated. Two major global events-the COVID-19 pandemic and racial and social equity travesties-have greatly influenced the discussions across these articles in our series, and these events will undoubtedly have an impact on future conversations about practices in patient-centered care. We want to thank Dr. Gao and the Fournal of Hospital Management and Health Policy editorial team, and especially Ms. Teresa Lin, for their wonderful support that enabled the development and publication of these important articles. Ultimately, we hope that this collection improves the experience and outcomes of the most important stakeholder of health care: the patient.

\section{Acknowledgments}

Funding: None.

\section{Footnote}

Provenance and Peer Review: This article was commissioned by the editorial office, Fournal of Hospital Management and Health Policy for the series "Innovations and Practices that Influence Patient-Centered Health Care Delivery". The article did not undergo external peer review.

Conflicts of Interest: All authors have completed the ICMJE uniform disclosure form (available at https://jhmhp.amegroups. com/article/view/10.21037/jhmhp-21-32/coif). The series "Innovations and Practices that Influence Patient-Centered Health Care Delivery" was commissioned by the editorial office without any funding or sponsorship. NF, SMB and ASM served as the unpaid Guest Editors of the series. NF serves as an unpaid editorial board member of fournal of Hospital Management and Health Policy from December 2019 to November 2021. The authors have no other conflicts of interest to declare.

Ethical Statement: The authors are accountable for all aspects of the work in ensuring that questions related to the accuracy or integrity of any part of the work are appropriately investigated and resolved.

Open Access Statement: This is an Open Access article distributed in accordance with the Creative Commons AttributionNonCommercial-NoDerivs 4.0 International License (CC BY-NC-ND 4.0), which permits the non-commercial replication and distribution of the article with the strict proviso that no changes or edits are made and the original work is properly cited (including 
links to both the formal publication through the relevant DOI and the license). See: https://creativecommons.org/licenses/ by-nc-nd/4.0/.

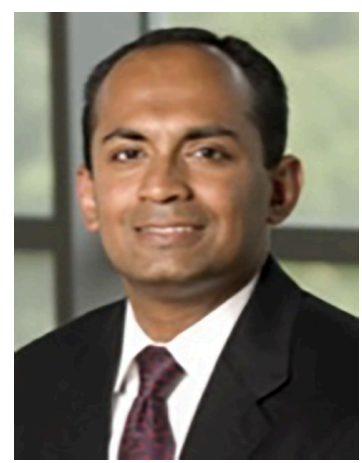

Naleef Fareed

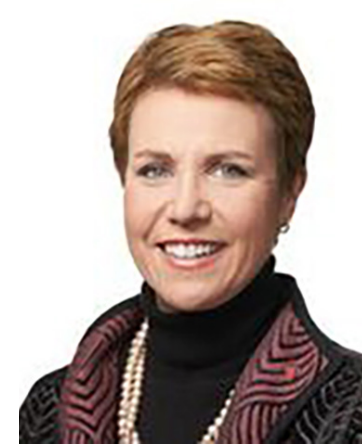

Susan Moffatt-Bruce

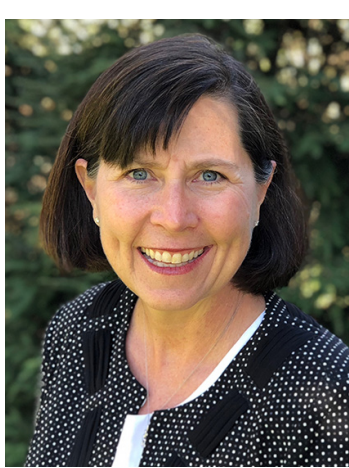

Ann Scheck McAlearney

Naleef Fareed ${ }^{\wedge}$

Department of Biomedical Informatics, The Center for the Advancement of Team Science, Analytics, and Systems Thinking (CATALYST), The Obio State University College of Medicine, Columbus, OH, USA. (Email: fareed.5@osu.edu) Susan Moffatt-Bruce ${ }^{\wedge}$ Royal College of Physicians and Surgeons of Canada, Ottawa, Canada. (Email: smoffattbruce@royalcollege.ca) Ann Scheck McAlearney^ Department of Family and Community Medicine, The Center for the Advancement of Team Science, Analytics, and Systems Thinking, The Obio State University College of Medicine,Columbus, OH, USA. (Email: Ann.McAlearney@osumc.edu) Received: 22 April 2021; Accepted: 28 May 2021; Published: 25 March 2022. doi: $10.21037 /$ jhmhp-21-32 View this article at: https://dx.doi.org/10.21037/jhmhp-21-32

doi: $10.21037 /$ jhmhp-21-32

Cite this article as: Fareed N, Moffatt-Bruce S, McAlearney AS. Innovations and Practices that Influence Patient-Centered Health Care Delivery Special Series. J Hosp Manag Health Policy 2022;6:1.

^ ORCID: Naleef Fareed, 0000-0001-8764-1625; Susan Moffatt-Bruce, 0000-0002-0999-5505; Ann Scheck McAlearney, 0000-0001-91075419 . 